\title{
Sulfadiazine-induced Crystalluria and Renal Failure in a Patient With AIDS
}

Cerebral toxoplasmosis is one of the most treatable opportunistic infections of the central nervous system in patients with the acquired immunodeficiency syndrome (AIDS). ${ }^{1,2}$ A combination of sulfadiazine and pyrimethamine is the therapy of choice, producing a favorable clinical response in 68 to 95 percent of patients receiving this regimen. ${ }^{3,4}$ Reports of sulfadiazine-induced crystalluria and renal failure were common during the 1940 s and 1950s, before more soluble sulfonamides, such as trimethoprim-sulfamethoxazole (TMP/SMX), became available. Recently, case reports of sulfadiazine nephrotoxicity have reappeared as widespread use of this regimen for human immunodeficiency virus (HIV)-related cerebral toxoplasmosis increased..$^{5-17}$ We report a patient with AIDS and central nervous system toxoplasmosis who developed nonoliguric renal failure caused by sulfadiazine-induced crystalluria.

\section{Case Report}

A 42-year-old man with AIDS was admitted to the hospital in November 1996 with an 1-day history of urinary incontinence and confusion. At admission he reported poor appetite and a mild headache not associated with fever, neck pain, or photophobia.

Three weeks earlier he had complained of 2 to 3 weeks of watery diarrhea, mild abdominal pain, some lightheadedness, and a low-grade fever (temperature of $99^{\circ} \mathrm{F}$ ), which responded to antimotility agents and discontinuation of saquinavir monotherapy. He denied chills, dysuria, nausea, vomiting, or anorexia. At that time his serum creatinine

Submitted, revised 9 June 1998.

From the Department of Clinical Pharmacy (BJD), Division of Nephrology (RAR), and the Department of Family and Community Medicine (BJD, RHG), University of California at San Francisco General Hospital, San Francisco. Address reprints to Betty J. Dong, PharmD, University of California School of Pharmacy, Department of Clinical Pharmacy, C-152, San Francisco, CA 94143-0622. was elevated to $3.7 \mathrm{mg} / \mathrm{dL}$ compared with his baseline of $1.0 \mathrm{mg} / \mathrm{dL}$. The patient was instructed to begin oral rehydration, but follow-up did not occur until admission. Stool cultures for ova and parasites were negative. His hemoglobin was 7.3 $\mathrm{g} / \mathrm{dL}$, hematocrit 24.0 percent, and white blood cell count $3400 / \mu \mathrm{L}$. His CD4+ lymphocyte count was $3 / \mathrm{L}$ and his HIV-1 RNA by branched DNA assay was 365,600 copies $/ \mathrm{mL}$.

HIV disease had been diagnosed in 1993 when his CD4+ lymphocyte count was $289 / \mathrm{L}$. The patient felt well, had no opportunistic infections or HIV-related sequelae, and repeatedly declined to take or adhere to prescribed medications. One double-strength TMP/SMX tablet daily was prescribed for Pneumocystis carinii pneumonia (PCP) and toxoplasmosis (positive toxoplasmosis antibody titer) prophylaxis when his CD4+ lymphocyte count was $165 / \mathrm{L}$, but adherence was poor. In February 1996 cerebral toxoplasmosis was diagnosed by a computed tomographic (CT) scan, and he began treatment with pyrimethamine and sulfadiazine. His adherence was inconsistent, however, and 2 months later he was readmitted for an exacerbation of cerebral toxoplasmosis and edema. Renal function at that time was normal (serum creatinine $1.0 \mathrm{mg} / \mathrm{dL}$ ). Subsequently, adherence was improved by home visits and a medication-dispensing device. Antiretroviral therapy was started in August 1996 when he agreed to start taking only saquinavir (Invirase) monotherapy $600 \mathrm{mg}$ three times a day.

He had no previous history of diabetes, hypertension, or renal disease. His medical history was also notable for treated neurosyphilis and untreated Mycobacterium avium complex (MAC) disease. Blood cultures, obtained 3 weeks earlier, became positive for MAC just before hospital admission, so treatment had not yet begun. On admission his medications included one doublestrength TMP/SMX tablet three times weekly for 


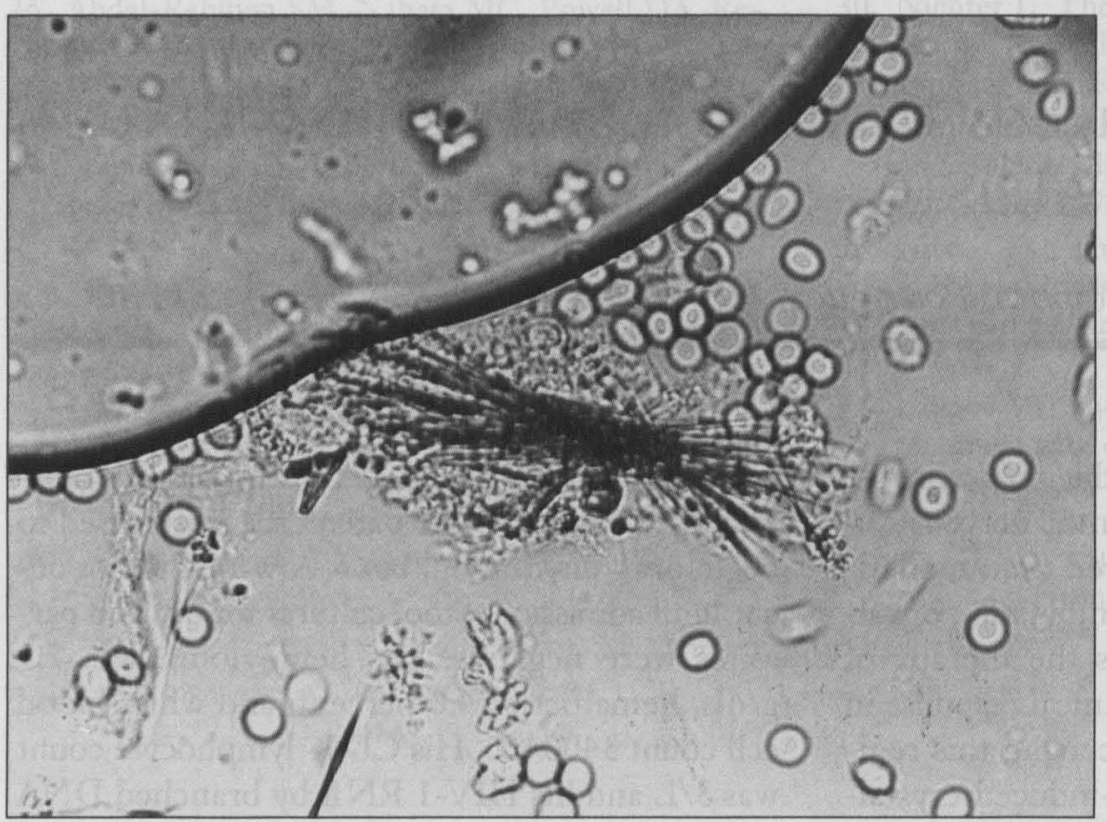

Figure 1. Admission urine sample showing multiple sulfadiazine "shock of wheat" crystals (air bubble on upper left of figure).

PCP prophylaxis, pyrimethamine $100 \mathrm{mg}$ daily, sulfadiazine $1.5 \mathrm{~g}$ every 6 hours, and folinic acid 25 $\mathrm{mg}$ daily for treatment of cerebral toxoplasmosis. The toxoplasmosis medications had not been reduced to maintenance doses because the primary care provider did not perceive that medication adherence was adequate. The patient denied use of other medications, including nonsteroidal anti-inflammatory agents.

When examined, the patient was alert but cachectic and confused. Neurologically he was oriented to name only, he had an intact gag reflex, and there was no asterixis or clonus. His motor strength was normal with symmetric reflexes (2+) in the upper and lower extremities. Findings from examinations of the cranial nerve, senses, and coordination were normal. Plantar reflexes were down-going. His temperature and blood pressure were normal, but his pulse was 124 beats per minute and respirations were $18 / \mathrm{min}$. Findings from a chest, heart, and abdominal examination were within normal limits. There was no costovertebral tenderness, and his extremities were without cyanosis, clubbing, or edema.

Notable laboratory findings included a normal serum sodium of $145 \mathrm{mEq} / \mathrm{L}$, a low bicarbonate $(8$ $\mathrm{mEq} / \mathrm{L})$, and elevations in potassium $(5.1 \mathrm{mEq} / \mathrm{L})$, chloride $(110 \mathrm{mEq} / \mathrm{L})$, blood urea nitrogen $(74$ $\mathrm{mg} / \mathrm{dL})$, serum creatinine $(12.2 \mathrm{mg} / \mathrm{dL})$, and serum phosphate $(12.1 \mathrm{mg} / \mathrm{dL})$, with an anion gap of $32 \mathrm{mEq} / \mathrm{L}$. The white blood cell count was
$700 / \mu \mathrm{L}$ with 72.4 percent neutrophils and an absolute neutrophil count of $500 / \mu \mathrm{L}$. The hemoglobin and hematocrit were $7.5 \mathrm{~g} / \mathrm{dL}$ and 24.5 percent, respectively, with a mean corpuscular volume of $76 \mu^{3}$. Values for the alkaline phosphate $(578$ $\mathrm{U} / \mathrm{L})$, aspartate aminotransferase (106 U/L), amylase (419 U/L), and creatinine kinase (544 $\mathrm{U} / \mathrm{L})$ were all elevated. Albumin was slightly low at $3.2 \mathrm{~g} / \mathrm{dL}$.

Serologic studies for hepatitis were negative for hepatitis A and C antibodies and hepatitis B surface antigen but positive for antibodies to hepatitis B. Glucose, calcium, magnesium, bilirubin, thyroid function, cryptococcal antigen, and syphilis test results were within normal limits. Urinalysis findings were notable for a $\mathrm{pH}$ of 6.0 , positive esterase, protein $(3+)$, glucose $(2+)$, blood (3+), red blood cells too numerous to count, 20 to 50 white blood cells, granular casts, and multiple sulfadiazine "shock of wheat" crystals (Figure 1). Urine and blood cultures were negative at 48 hours after admission. A chest radiograph showed normal cardiac and mediastinal silhouettes and no infiltrates. A renal sonogram showed right hydronephrosis and multiple echogenic foci in the kidney (Figure 2). A head CT scan without contrast showed communicating hydrocephalus and no recurrence of toxoplasmosis.

The diagnosis of nonoliguric renal failure caused by obstructive sulfadiazine crystals was suspected. The cause of the altered mental status was 
Figure 2. Sonogram of kidney showing multiple echogenic foci (sulfadiazine stones) with shadowing.

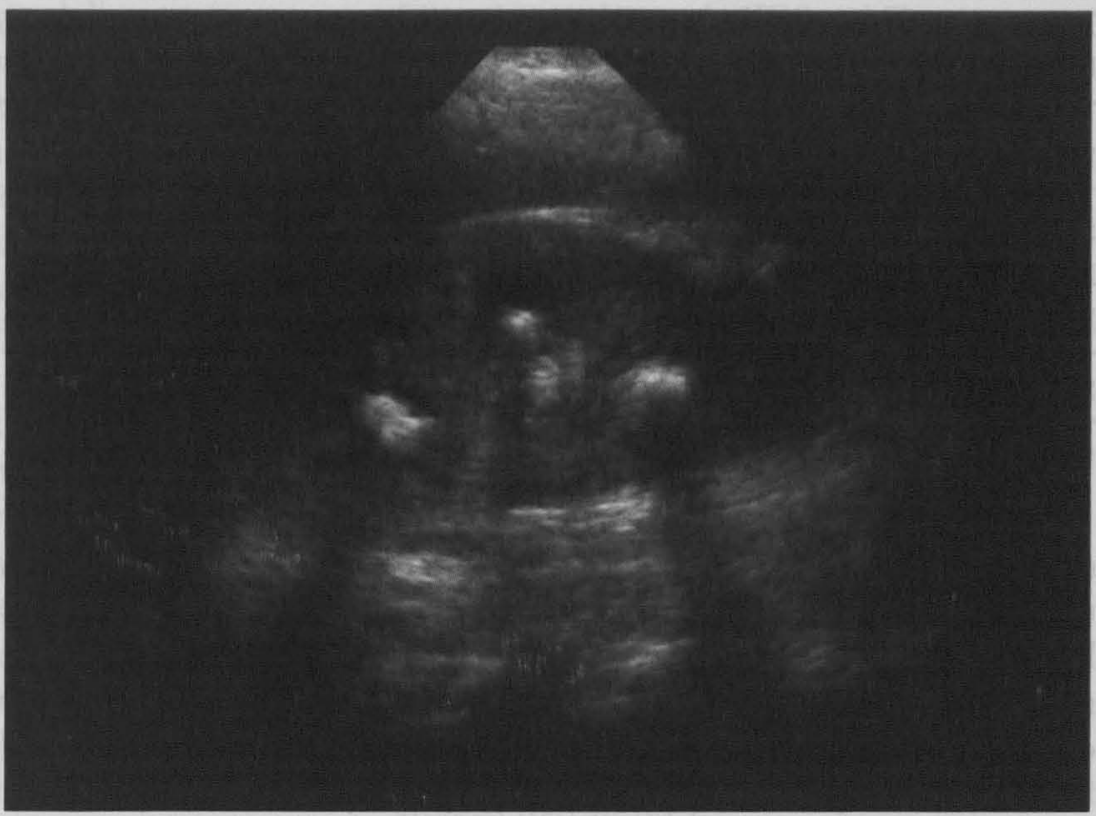

believed to be multifactorial and included such contributory factors as uremia, dehydration, possible urinary tract infection, central nervous system toxoplasmosis with hydrocephalus, and AIDS dementia. The neutropenia was ascribed to drug toxicity or MAC infection, and the elevations in liver function tests were presumed secondary to MAC disease or HIV-related cholecystopathy and biliary disease.

\section{Hospital Course}

Sulfadiazine was stopped and antitoxoplasmosis treatment was changed to clindamycin $600 \mathrm{mg}$ every 6 hours intravenously, pyrimethamine $50 \mathrm{mg}$ every other day by mouth, and folinic acid $25 \mathrm{mg}$ daily by mouth. Ceftriaxone was given empirically for 7 days to treat a possible urinary tract infection, but urine and blood cultures remained negative. Initially, vigorous intravenous hydration with 5 percent dextrose in normal saline was administered. Satisfactory urine output was maintained but the acidosis and renal function did not improve. On day 2 , three ampules of sodium bicarbonate $(50 \mathrm{mEq}$ per ampule) in $1 \mathrm{~L}$ of dextrose 5 percent water (D5W) was infused at $150 \mathrm{~mL} / \mathrm{h}$ to treat the acidosis and to increase the urine $\mathrm{pH}$ to 7 .

During the next 3 to 4 days, hydration and alkalization were gradually reduced to one ampule of sodium bicarbonate in D5W at $100 \mathrm{~mL} / \mathrm{h}$ to maintain the appropriate urine $\mathrm{pH}$ and serum bicarbonate values. Sodium bicarbonate therapy was dis- continued after 2 days (days 4 and 5 of bicarbonate therapy) because of metabolic alkalosis (serum bicarbonate of $36 \mathrm{mmol} / \mathrm{L}$ and urine $\mathrm{pH} 9.0$ ). Resolution of the renal failure and improvement in mental status occurred after 3 to 4 days of aggressive hydration and bicarbonate therapy.

At discharge on hospital day 15, the patient's serum creatinine was $1.2 \mathrm{mg} / \mathrm{dL}$, blood urea nitrogen was $9 \mathrm{mg} / \mathrm{dL}$, and all electrolytes were normal except for elevated chloride $(111 \mathrm{mEq} / \mathrm{L})$ and slightly low bicarbonate $(18 \mathrm{mEq} / \mathrm{L})$ levels. A urinalysis on discharge was normal with a $\mathrm{pH}$ of 6.0 , and no sulfadiazine crystals were seen. A second sonogram was not ordered because his renal function had returned to baseline. Transaminase values normalized, but alkaline phosphatase remained elevated. Blood counts increased toward normal but remained suppressed. Discharge medications included clarithromycin and ethambutol for treatment of MAC disease, dapsone for PCP prophylaxis, and clindamycin and pyrimethamine for maintenance of cerebral toxoplasmosis.

\section{Discussion}

Renal toxicity, crystalluria, and nephrolithiasis are serious complications of sulfadiazine therapy in HIV-infected persons. ${ }^{5-17}$ Other agents that can produce a similar clinical picture include indinavir and intravenous acyclovir, but not oral acyclovir (Table 1). ${ }^{18-21}$

Predisposing factors for sulfadiazine renal toxi- 
Table 1. Principal Drugs Causing Crystalluria, Renal Stones, and Renal Failure in Persons Infected With the Human Immunodeficiency Virus.

\begin{tabular}{lccccc}
\hline Drug & Crystalluria & $\begin{array}{c}\text { Renal } \\
\text { Stones }^{*}\end{array}$ & $\begin{array}{c}\text { Renal } \\
\text { Failure }\end{array}$ & $\begin{array}{c}\text { Hydration } \\
\text { Indicated }\end{array}$ & $\begin{array}{c}\text { Alkalization } \\
\text { Indicated }\end{array}$ \\
\hline Sulfadiazine & Yes & Yes & Yes & Yes & Yes \\
Intravenous acyclovir ${ }^{\dagger}$ & Yes & No & Yes & Yes & Unknown \\
Indinavir & Yes & Yes & Yes & Yes & No \\
\hline
\end{tabular}

From Kopp et al, ${ }^{18}$ Daudon et al, ${ }^{19}$ Berns et al, ${ }^{20}$ and Don et al..$^{21}$ *Diagnosis by renal sonography or computed tomographic scan.

†Does not apply to oral acyclovir.

city in this patient were diarrhea and the inability to adhere to instructions for rehydration. Nonadherence also postponed reduction of antitoxoplasmosis treatment doses to the lower maintenance doses, which might have decreased the potential for renal toxicity. Nonadherence was especially detrimental in other aspects of his HIV care, such as the lack of standard prophylaxis against MAC disease, PCP, and toxoplasmosis, and his inability to take potent antiretroviral drug combinations that have clearly been shown to reduce morbidity and prolong survival. ${ }^{22-24}$ Adherence might have been improved by the elimination of TMP/SMX therapy, because the combination of sulfadiazine and pyrimethamine appears equally effective for PCP and toxoplasmosis prophylaxis. ${ }^{25}$ Strategies to improve adherence have been described. ${ }^{26}$

This patient's clinical condition, urinary sediment findings, nonoliguric renal failure, sonography findings, and hospital course are consistent with other reported cases of sulfadiazine-induced renal failure. ${ }^{5-17}$ The incidence of sulfadiazine-related crystalluria is reported as 8 to 29 percent, whereas renal dysfunction is observed in 2.0 to 7.5 percent of $\mathrm{HIV}$-positive cases, twice the incidence in HIV-negative persons. ${ }^{7,10,12}$ Typically the patient complains of flank, lumbar, or abdominal pain (80 percent of patients), oliguria or anuria, and hematuria. Symptoms are usually delayed, developing in most patients 1 to 4 weeks after beginning therapy, but they can occur at any time. The diagnosis of sulfadiazine-induced renal failure is confirmed by a urine $\mathrm{pH}$ of less than 6 and classic "shock of wheat" (acetyl) sulfadiazine crystalluria, hematuria, and pyuria. Renal sonographic findings can show unilateral or bilateral hydronephrosis or echogenic densities caused by sulfadiazine stones, or they can be normal. ${ }^{7,8}$

Acute renal failure secondary to sulfadiazine crystallization is a predictable toxicity that should be anticipated in patients who develop concomitant dehydration and acidosis from diarrhea, poor fluid intake, or other causes of fluid losses. A retrospective review of 35 patients with sulfadiazine-induced crystalluria and renal dysfunction found that most had normal renal function and no history of renal damage before starting sulfadiazine. ${ }^{7}$ Risk factors included a history of volume depletion from poor fluid intake, diarrhea, fever, or administration of radiocontrast dye. Hypoalbuminemia can also predispose to renal toxicity by increasing the serum levels of the free drug. ${ }^{7}$

Factors that decrease sulfadiazine solubility should be avoided. Sulfadiazine is acetylated in the liver to form insoluble metabolites that can precipitate in the renal tubules during volume depletion or low urinary $\mathrm{pH}$. The critical urine $\mathrm{pH}$ value that maintains crystal solubility is reported to be 7.15.27,28 The concurrent use of drugs, such as ascorbic acid, that can acidify the urine $\mathrm{pH}$ might also predispose to renal toxicity by decreasing drug solubility. Likewise, the concurrent administration of sulfadiazine with indinavir might create problems, as indinavir crystallization can occur in an alkaline urine $\mathrm{pH} .{ }^{18-20}$

Acute treatment requires aggressive intravenous hydration to maintain a daily urinary output of at least $1.5 \mathrm{~L}$ and bicarbonate alkalization to achieve a urine $\mathrm{pH}$ of greater than 7.5 . If renal function does not improve immediately, hemodialysis is indicated to relieve symptoms of pericarditis and tamponade, asterixis, severe acidosis, hyperkalemia, or severe uremic symptoms unresponsive to aggressive medical interventions. If there is complete obstruction, urethral catheterization or nephrostomy tube placement, followed by warm 5 percent sodium bicarbonate lavage, can be successful ${ }^{14,15}$ Complete reversal of renal failure generally 
occurs unless there is coexisting renal diseases (eg, HIV nephropathy). It is not essential to avoid further sulfadiazine therapy if adequate hydration can be maintained and dehydration avoided. Complete resolution of the crystalluria and nephrolithiasis has been reported even when sulfadiazine was continued, but this approach is not recommended because treatment with clindamycin-primaquine appears equally effective. ${ }^{16,17}$

Sulfadiazine-induced renal toxicity and nephrolithiasis are preventable if patients maintain a fluid intake of $2 \mathrm{~L} / \mathrm{d}$, an adequate urine output of at least $2 \mathrm{~L} / \mathrm{d}$, and a urine $\mathrm{pH}$ greater than 7 . Oral sodium bicarbonate 6 to $12 \mathrm{~g} / \mathrm{d}$ might be required to achieve an alkaline urine $\mathrm{pH}$. Increasing the urine $\mathrm{pH}$ is especially important in those patients who have a history of sulfadiazine nephrotoxicity and who require continued sulfadiazine therapy. $\mathrm{Pa}$ tients should be instructed to report immediately any symptoms of fluid losses, flank, lumbar, or abdominal pain, urinary symptoms, or blood in the urine. Renal function, urinary $\mathrm{pH}$, and fluid status should be closely monitored on a regular basis, weekly if there is an increase in diarrhea or other volume losses.

Primary care providers should be aware that sulfadiazine can cause renal toxicity and should be knowledgeable about available strategies to minimize toxicity, including careful adherence to hydration. Patients who are unable or unwilling to maintain adequate fluid intake or who are prone to volume depletion from gastrointestinal losses should be considered poor candidates for sulfadiazine therapy.

\section{References}

1. Newton HB. Common neurologic complications of HIV-1 infection and AIDS. Am Fam Physician 1995;51:387-98.

2. Simpson DM, Tagliati M. Neurologic manifestations of HIV infection. Ann Intern Med 1994;121: 769-85.

3. Katlama C, DeWit S, O'Doherty E, Van Glabeke $M$, Clumeck N. Pyrimethamine-clindamycin vs. pyrimethamine-sulfadiazine as acute and long-term therapy for toxoplasmic encephalitis in patients with AIDS. Clin Infect Dis 1996;22:268-75.

4. Wong SY, Israelski DM, Remington JS. AIDS-associated toxoplasmosis. In Sande MA, Volberding P, editors. Medical management of AIDS. 4th ed. Philadelphia: WB Saunders, 1995.

5. Diaz F, Collazos J, Mayo J, Martinez E. Sulfadiazine-induced multiple urolithiasis and acute renal failure in a patient with AIDS and Toxoplasma encephalitis. Ann Pharmacother 1996;30:41-2.

6. Farinas MC, Echevarria S, Sampedro I, Gonzalez A, Perez del Molino A, Gonzalez-Macias J. Renal failure due to sulphadiazine in AIDS patients with cerebral toxoplasmosis. J Intern Med 1993;233:365-7.

7. Becker K, Jablonowski $H$, Haussinger D. Sulfadiazine-associated nephrotoxicity in patients with the acquired immunodeficiency syndrome. MedicineBaltimore 1996;75:185-94.

8. Kane D, Murphy JM, Keating S, Wilson GF, Mulcahy FM. Renal ultrasonic findings in sulphadiazineinduced renal failure. $\mathrm{Br} J$ Radiol 1996;69:925-8.

9. de Sequera $P$, Albalate $M$, Hernandez J, Vasquez A, Abad J, Ramiro E, et al. Acute renal failure due to sulphadiazine crystalluria in AIDS patients. Postgrad Med J 1996;72:557-8.

10. Hein R, Brunkhorst R, Thon WF, Schedel I, Schmidt RE. Symptomatic sulfadiazine crystalluria in AIDS patients: a report of two cases. Clin Nephrol 1993;39:254-6.

11. Goadsby PJ, Donaghy AJ, Lloyd AR, Wakefield D. Acquired immunodeficiency syndrome (AIDS) and sulfadiazine-associated acute renal failure. Ann Intern Med 1987;107:783-4.

12. Molina JM, Belenfant X, Doco-Lecompte T, Idatte $\mathrm{JM}$, Modai J. Sulfadiazine-induced crystalluria in AIDS patients with Toxoplasma encephalitis. AIDS 1991;5:587-9.

13. Carbone LG, Bendixen B, Appel GB. Sulfadiazineassociated obstructive nephropathy occurring in a patient with the acquired immunodeficiency syndrome. Am J Kidney Dis 1988;12:72-5.

14. Winterborn MH, Mann JR. Anuria due to sulfadiazine. Arch Dis Child 1973;48:915-7.

15. Dorfman LE, Smith JP. Sulfonamide crystalluria: a forgotten disease. J Urol 1970;104:482-3.

16. Oster S, Hutchinson F, McCabe R. Resolution of acute renal failure in toxoplasmic encephalitis despite the continuance of sulfadiazine. Rev Infect Dis 1990;12:618-20.

17. Ventura MG, Wybran J, Farber CM. Sulfadiazine revisited. J Infect Dis 1989;160:556-7.

18. Kopp JB, Miller KD, Mican JM, Feuerstein IM, Vaughan E, Baker C, et al. Crystalluria and urinary tract abnormalities associated with indinavir. Ann Intern Med 1997;127:119-25.

19. Daudon M, Estepa L, Viard JP, Joly D, Jungers $P$. Urinary stones in $\mathrm{HIV}-1$ positive patients treated with indinavir. Lancet 1997;349:1294-5.

20. Berns JS, Cohen RM, Silverman M, Turner J. Acute renal failure due to indinavir crystalluria and nephrolithiasis: report of two cases. Am J Kidney Dis 1997;30:558-60.

21. Don B, Rodriguez RA, Humphreys MH. Acute renal failure associated with pigmenturia or crystal deposits. In: Schrier RW, Gottschalk CW, editors. Diseases of 
the kidney. 6th ed. Boston: Little, Brown, 1997.

22. Centers for Disease Control and Prevention. Report of the NIH Panel to define principles of therapy of HIV infection and guidelines for the use of antiretroviral agents in HIV-infected adults and adolescents. MMWR Morbid Mortal Weekly Rep 1998; 47(RR-5):1-83.

23. Masur H. Prevention and treatment of Pneumocystis pneumonia. N Engl J Med 1992;327:1853-60.

24. Centers for Disease Control and Prevention. Recommendations on prophylaxis and therapy for disseminated Mycobacterium avium complex for adults and adolescents infected with human immunodeficiency virus. US Public Health Service Task Force on Prophylaxis and Therapy for Mycobacterium avium Complex. MMWR Morbid Mortal Weekly $\frac{C}{3}$ Rep 1993;42(RR-9):14-20.

25. Heald A, Flepp M, Chave JP, Malinverni R, Ruttimann S, Gabriel V, et al. Treatment for cerebral toxoplasmosis protects against Pneumocystis carinii ฏ pneumonia in patients with AIDS. The Swiss HIV Cohort Study. Ann Intern Med 1991;115:760-3.

26. Goldschmidt RH, Balano KB, Legg JL, Dong BJ. Individualized strategies in the era of combination $\overrightarrow{\vec{F}}$ antiretroviral therapy. J Am Board Fam Pract 1998; 11:158-64.

27. Weinstein L, Madoff MA, Samet CM. The sulfonamides. N Engl J Med 1960;263:793-800.

28. Appel GB, Neu HC. The nephrotoxicity of antimicrobial agents. N Engl J Med 1977;296:784-7. 